\title{
Ha-ras oncogene effect on DNA content and chromatin supraorganization in benzo[a]pyrene-transformed human breast epithelial cells
}

\author{
Maria Luiza S. Mello a,*, \\ Benedicto de Campos Vidal ${ }^{\mathrm{a}}$ and Jose Russo ${ }^{\mathrm{b}}$ \\ ${ }^{a}$ Department of Cell Biology, Institute of Biology, \\ UNICAMP, 13083-970 Campinas, SP, Brazil \\ ${ }^{\mathrm{b}}$ Breast Cancer Research Laboratory, Fox Chase \\ Cancer Center, Philadelphia, PA19111, USA
}

Received 12 February 1999

Accepted 1 June 1999

When transfected to benzo[a]pyrene (BP)-transformed MCF-10F human breast epithelial cells (BP1 cell line) the c-Ha-ras oncogene has proven to enhance the neoplastic changes initiated by exposure to $\mathrm{BP}$, giving rise to an aggressive tumorigenic cell line, BP1-Tras. We have previously demonstrated by image analysis that BP affects the DNA content and the chromatin supraorganization of MCF-10F cells. Here Feulgen-stained BP1-Tras cells were studied by image analysis in order to evaluate possible additional changes in DNA content and chromatin texture induced by insertion of the ras oncogene. A high variability in DNA content also including polyploidy or near-polyploidy, and an increase in the packing states of the chromatin which became still condensed in BP1 cells were found in BP1-Tras cells. The results differed from those reported for the BP1-E1 cell line which is also an aggressive tumorigenic cell line, but was attained through progressive passages of BP-transformed cells. It was demonstrated that different patterns of changes in DNA content and chromatin organization may be involved in equally aggressive tumorigenic BP-transformed cell lines originated from the same cell line by different mechanisms.

Keywords: Human breast epithelial cells, benzo[a]pyrene, Ha-ras, DNA content, chromatin supraorganization, image analysis

\footnotetext{
${ }^{*}$ Corresponding author. Fax: +55 19 7887821;

E-mail: mlsmello@obelix.unicamp.br.
}

\section{Introduction}

The MCF-10 cell line has been reported as the first spontaneous line of cultured breast epithelium for which there is direct evidence that the normal diploid chromosome pattern of the explanted tissues was retained for over a year of growth culture [14]. This cell line gave rise to MCF-10A and MCF-10F cells [14].

Immortal human breast epithelial cells, MCF-10F, which exhibit characteristics of normal cells [14], have been successfully transformed in vitro with benzo[a]pyrene, giving rise to several cell lines (BP1, BP1-E, BP1-E1, among others) [3]. The transformed nontumorigenic BP1 cells generated the BP1-E cell line and this one the BP1-E1 cells. BP1-E and BP1-E1 cells have been shown to develop neoplastic tumorigenesis, growing as tumors in SCID mice [3].

Benzo[a]pyrene (BP) has been found to affect the c-Ha-ras gene at the early stage of the MCF-10F cell transformation (BP1 cell line), resulting in the loss of one of the alleles $(1.0 \mathrm{~kb})$ of the gene and a mutation of the remaining allele at the first position of codon 12 or codon 61 [22]. However, the subsequent steps of the neoplastic process in the BP-transformed MCF$10 \mathrm{~F}$ cells have been reported to involve the action of other genes [2,19,20,22].

BP-elicited tumorigenesis in MCF-10F cells has been found to be accompanied by changes in DNA content, nuclear and nucleolar morphometric features and chromatin texture as studied by image analysis [1, 17]. A decrease in DNA amount and nuclear areas and an increase in chromatin packing state higher order, developed with BP transformation were found to become enhanced with the tumorigenic progression [17].

Transfection of the c-Ha-ras oncogene to transformed BP1 cells originated the BP1-Tras cell line which exhibited enhancement of the neoplastic changes 
initiated by exposure to BP, leading to the expression of a tumorigenic phenotype as aggressive as that of BP1E1 cells in SCID mice [4]. The c-Ha-ras gene was thus assumed to be potentially involved both in early and late steps of in vitro tumor progression [4].

The question of whether tumorigenesis originated by transfection of the c-Ha-ras oncogene to BP1 cells was accompanied by changes in patterns of DNA content and chromatin supraorganization comparable to those detected in progressively tumorigenic BP1-E1 cells has not been solved as yet. These chromatin characteristics were thus investigated here in Feulgenstained BP1-Tras cells by image analysis procedures and compared with data for BP1 and MCF-10F cells, and with data previously reported for the BP1-E1 cell line. Part of the results have been communicated in the 89th Annual Meeting of the American Association for Cancer Research [11].

\section{Materials and methods}

\subsection{Cell lines and culture conditions}

Nontransformed cells (MCF-10F), benzo[a]pyrenetransformed BP1 cells, and the BP1-Tras cell line obtained by transfection of BP1 cells with the c-Ha-ras oncogene [4] were used. The MCF-10F cells used were at passage 140, BP1 cells at passage 23, and BP1Tras at passage 61. The cells were grown in Dulbecco's minimal essential medium/F-12 medium (1 : 1) supplemented with $5 \%$ equine serum, $0.1 \mu \mathrm{g} / \mathrm{ml}$ cholera-toxin, $10 \mu \mathrm{g} / \mathrm{ml}$ insulin, $100 \mathrm{units} / \mathrm{ml}$ penicillin, $100 \mu \mathrm{g} / \mathrm{ml}$ streptomycin, $2.5 \mu \mathrm{g} / \mathrm{ml}$ amphotericin B (Gibco Island, NY), $0.5 \mu \mathrm{g} / \mathrm{ml}$ hydrocortisone (Sigma) and $0.02 \mu \mathrm{g} / \mathrm{ml}$ epidermal growth factor (Collaborative Research Inc., Palo Alto, CA), as described previously [14].

\subsection{Cell preparations and staining}

The cells grown on coverslips were fixed in an absolute ethanol-acetic acid mixture $(3: 1)$ for $1 \mathrm{~min}$, rinsed in $70 \%$ ethanol for $5 \mathrm{~min}$, air dried at room temperature, and subjected to the Feulgen reaction (hydrolysis: $4 \mathrm{M} \mathrm{HCl}$ at $21^{\circ} \mathrm{C}$ for $75 \mathrm{~min}$ ). The stained preparations were mounted in Canada balsam $\left(n_{\mathrm{D}}=\right.$ 1.54). The preparations were subjected to the Feulgen reaction and subsequently to dehydration steps, and were processed together in order to keep experimental conditions as constant as possible and to minimize opportunities for systematic errors.

\subsection{Video image analysis}

Data Translation, Inc. equipment was used for image acquisition, segmentation and featuring by means of the Global Lab Acquire Software ${ }^{\mathrm{TM}}$ (Marlboro, MA, USA).

The microscopic images were obtained with a Zeiss Pol-photomicroscope equipped with a Pol-Neofluar 25/0.60 objective, optovar 1.25, LD-Epiplan 16/0.30 condenser, and $\lambda=550 \mathrm{~nm}$. The half-band width at the spot of transmission does not exceed $15 \mathrm{~nm}$ at this wavelength for a light beam width equal to $2 \mathrm{~mm}$ [21], which was the width of the effective light beam used. The images to be processed were fed from the microscope into a Pentium 133 computer through a monochrome CCD (JVC TK-S240) video camera. In this investigation, $1 \mu \mathrm{m}=4.45$ pixels. The software provided quantitative information on nuclear size and Feulgen-DNA values. Absorbing areas (S), optical densities (OD), and integrated optical densities (IOD) were chosen from several descriptors provided by the software as more adequate for comparative purposes.

Since the study refers to cells in culture and an accurately performed Feulgen reaction was used, the background was homogeneously unstained. The threshold once achieved to establish the boundaries of the nuclei in MCF-10F cells was the same all over the monitor and extended to the various cell lines studied. The microscope used in the video image analysis procedure (Zeiss Pol-photomicroscope) has construction characteristics which reduce glare (straylight) effects and diffraction errors.

\subsection{Scanning microspectrophotometry image analysis}

Parameters previously used for studies of chromatin supraorganization in ras-transformed NIH 3 T3 cells $[8,9,12]$ and MCF-10A cells [10], and benzo[a]pyrenetransformed MCF-10F cells [17] were established from images obtained with a Zeiss automatic scanning microspectrophotometer interfaced to a personal computer.

Operating conditions were: objective 100/1.25, optovar 1.25 , measuring diaphragm diameter $=0.10 \mathrm{~mm}$, field diaphragm diameter $=0.20 \mathrm{~mm}, \lambda=565 \mathrm{~nm}$, photomultiplier R-928, $0.5 \mu \mathrm{m} \times 0.5 \mu \mathrm{m}$ scanning spot size, LD-Epiplan 16/0.30 condenser. The half-band width at the spot of transmission does not exceed $15 \mathrm{~nm}$ at this wavelength for a light beam width equal to $2 \mathrm{~mm}$ [21]. The width of the effective light beam 
used in this case was $0.2 \mathrm{~mm}$. The parameters obtained were those which permitted us to plot a scatter diagram as proposed by Vidal [15], relating Sc\% (nuclear relative area covered with stained chromatin presenting optical density values above a selected threshold level, in this case absorbance 0.200) vs AAR (a dimensionless parameter that expresses how many times the average absorbance of the "condensed" chromatin exceeds that of the entire nucleus). AAR $=$ $(\mathrm{Ac} / \mathrm{Sc}) /\left(\mathrm{A}_{\mathrm{T}} / \mathrm{S}_{\mathrm{T}}\right)$, where Ac, "condensed" chromatin Feulgen-DNA values; $A_{T}$, nuclear Feulgen-DNA values; Sc, "condensed" chromatin stained area; $\mathrm{S}_{\mathrm{T}}$, nuclear stained area [16].

\subsection{Statistics}

Calculations were performed using the Minitab 10 program.

\section{Results}

Image analysis results for BP1-Tras cells indicated a wide variability in their Feulgen-DNA values, reflected by respective standard deviation (SD) values (Figs 1 and 2; Table 1) and differing from the situation reported with the advancing tumorigenesis steps from BP1 to BP1-E1 cells, when the Feulgen-DNA values shifted to smaller IOD values [17]. The statistical tests confirmed that the Feulgen-DNA (IOD) amount distribution of the BP1-Tras differed from those of MCF10F (control) and BP1 cells (Table 2). ANOVA allowed analysis of means. However, since in some cases means were not representative of the cell populations, the nonparametric Mann-Whitney test for the difference between two population medians was used (Table 2).

The MCF-10F cells used as a control are expected to be in a near-diploid state since nearly $85 \%$ of these cells at passage 93 are diploid [14]. Consequently, in comparison with MCF-10F cell data, the FeulgenDNA content distribution histograms for cell lines derived from MCF-10F cells can be analyzed at least in terms of heterogeneity and of significant DNA aneuploidy and/or polyploidy [18].

Since Feulgen-DNA values within 100-200, 200400 , and $>400$ IOD ranges have been found in BP1Tras cells, the highest IOD values in this case are assumed to be accounted for by polyploid or nearpolyploid nuclei (Fig. 1). Tukey's box-and-whisker plots highlight outliers (asterisks) occurring preferen-
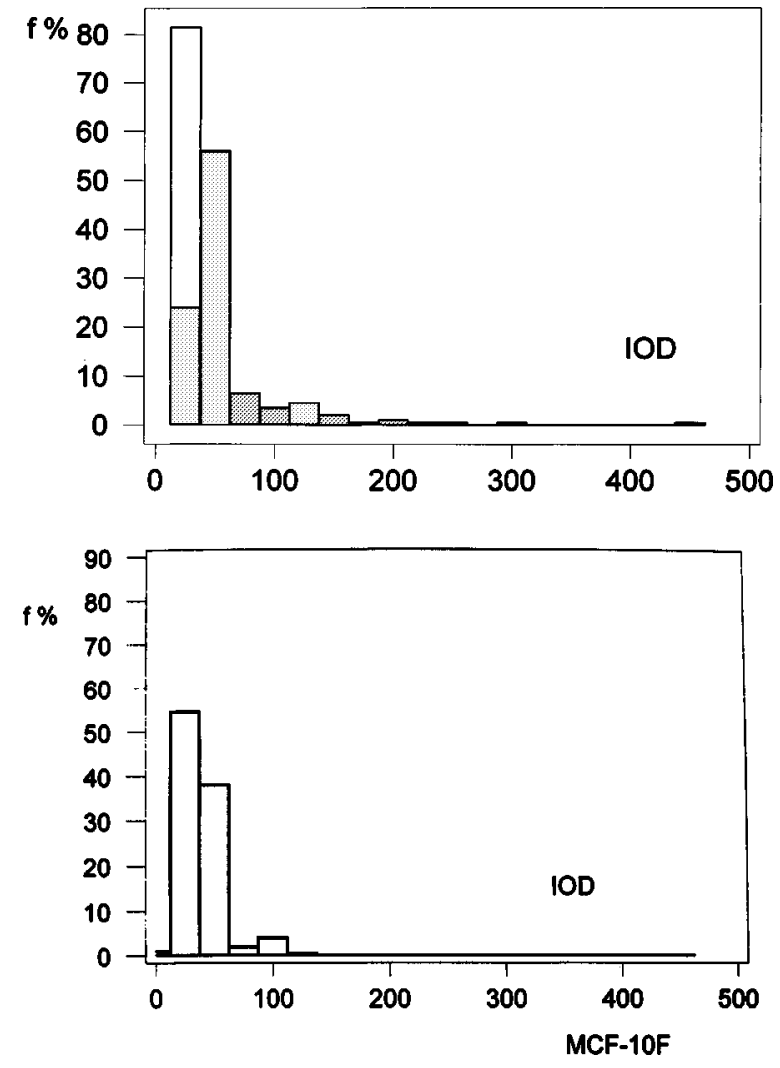

Fig. 1. Relative frequency $(f \%)$ histograms for the Feulgen-DNA content (IOD) of BP1-Tras cells (grey) in comparison with BP1-E1 cells (white) [top]. A histogram for MCF-10F cells is also shown for comparisons $(n=200)$ [bottom].

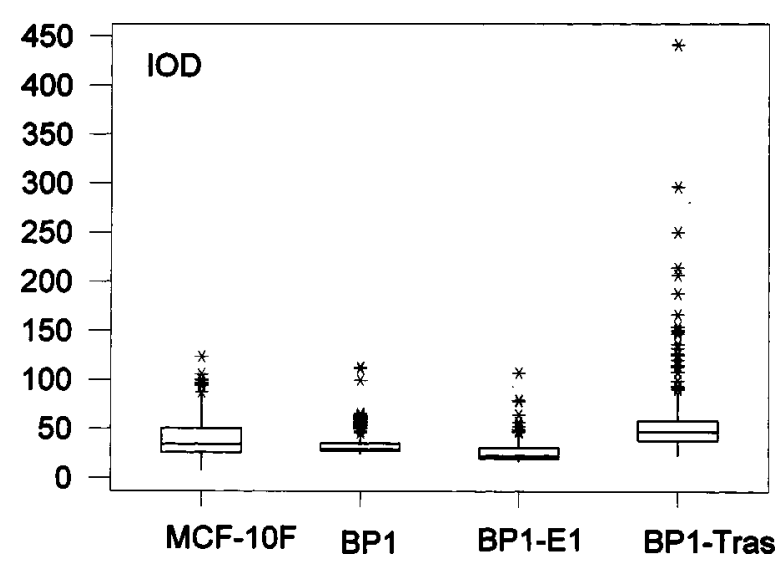

Fig. 2. Tukey's box-and-whisker plots for Feulgen-DNA content (IOD) of MCF-10F cell lines. Lower and upper traces $=$ lower and upper quartiles of the distributions; middle trace = median; $*=$ outliers. The plot for BP1-E1 cells was based on IOD values obtained previously [17]. 
Table 1

Video nuclear image parameters for Feulgen-stained MCF-10F cell lines $(n=200)$

\begin{tabular}{|c|c|c|c|c|c|c|}
\hline \multirow[b]{2}{*}{ Cells } & \multicolumn{2}{|c|}{ IOD } & \multicolumn{2}{|c|}{ OD } & \multicolumn{2}{|c|}{$S\left(\mu \mathrm{m}^{2}\right)$} \\
\hline & $\overline{\bar{X}}$ & SD & $\overline{\bar{X}}$ & SD & $\overline{\bar{X}}$ & SD \\
\hline BP1-Tras & 60.38 & 47.55 & 0.336 & 0.068 & 176.50 & 111.69 \\
\hline MCF-10F & 40.29 & 18.93 & 0.251 & 0.065 & 156.78 & 62.14 \\
\hline BP1 & 34.73 & 15.06 & 0.295 & 0.080 & 117.64 & 44.81 \\
\hline $\mathrm{BP} 1-\mathrm{E} 1^{\mathrm{a}}$ & 27.67 & 12.77 & 0.290 & 0.095 & 97.21 & 31.96 \\
\hline
\end{tabular}

a[17]; IOD, integrated optical density; OD, optical density; $S$, nuclear absorbing area; SD, standard deviation; $\bar{X}$, arithmetic mean.

Table 2

Comparison of nuclear image analysis parameters $(n=200)$

\begin{tabular}{llcc}
\hline Descriptors & Cells compared & Mann-Whitney $(P)$ & ANOVA $(F)$ \\
\hline Feulgen-DNA & MCF-10F, BP1-Tras & $0.0000^{* *}$ & \\
content, IOD & BP1, BP1-Tras & $0.0000^{* *}$ & \\
& BP1-E1, BP1-Tras & $0.0000^{* *}$ & \\
OD & MCF-10F, BP1-Tras & & $169.30^{* *}$ \\
$(=$ absorbances $)$ & BP1, BP1-Tras & $0.0000^{* *}$ & \\
& MCF-10F, BP1 & $0.0000^{* *}$ & $2.93^{\mathrm{a}}$ \\
& BP1, BP1-E1 & $30.77^{* *}$ \\
& BP1-E1, BP1-Tras & & \\
Nuclear absorbing area & MCF-10F, BP1-Tras & 0.9869 & \\
& BP1, BP1-Tras & $0.0000^{* *}$ & \\
& BP1-E1, BP1-Tras & $0.0000^{* *}$ & \\
\hline
\end{tabular}

*significant $\left(P_{0.05}\right.$ level $) ;{ }^{* *}$ highly significant $\left(P_{0.01}\right) ;{ }^{\text {a }}[17]$.

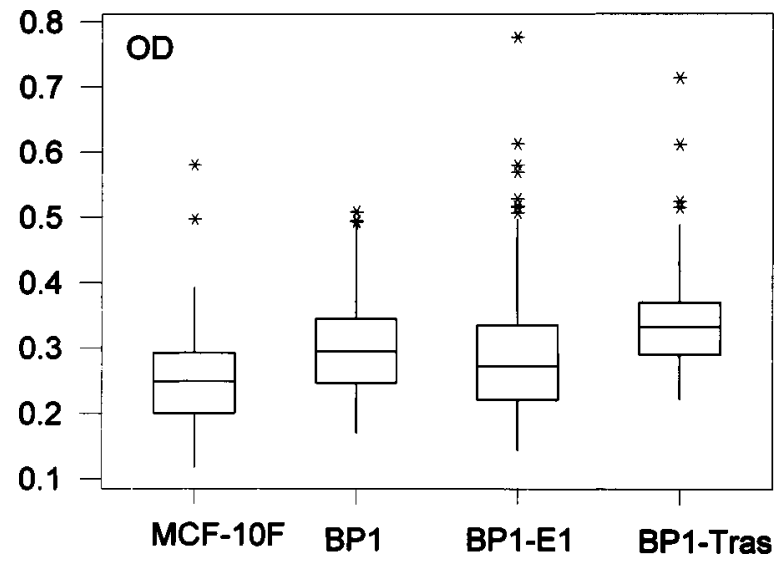

Fig. 3. Tukey's box-and-whisker plots for OD values of MCF-10F cell lines. Lower and upper traces $=$ lower and upper quartiles of the distributions; middle trace $=$ median; $*=$ outliers. The plot for BP1-E1 cells was based on OD values obtained previously [17].

tially outside the limits of the upper adjacent values (whiskers) and to a larger extent for Feulgen-DNA values and nuclear absorbing areas of BP1-Tras cells, which indicates that the phenomenon of polyploidy

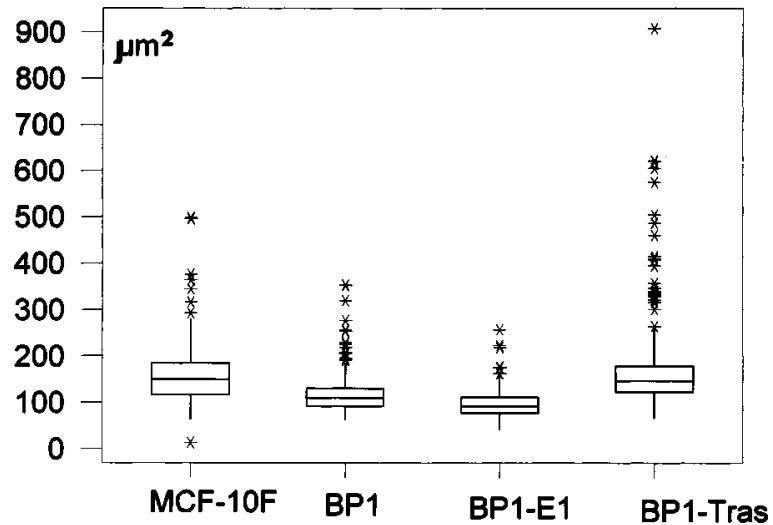

Fig. 4. Tukey's box-and-whisker plots for nuclear absorbing areas of Feulgen-stained MCF-10F cell lines. Lower and upper traces $=$ lower and upper quartiles of the distributions; middle trace $=$ median $; *=$ outliers. The plot for BP1-E1 cells was based on values obtained previously [17].

or near-polyploidy is especially frequent in these cells (Figs 2, 4).

On the other hand, 2C Feulgen-DNA aneuploidy was assumed to be represented by the extreme shift of 


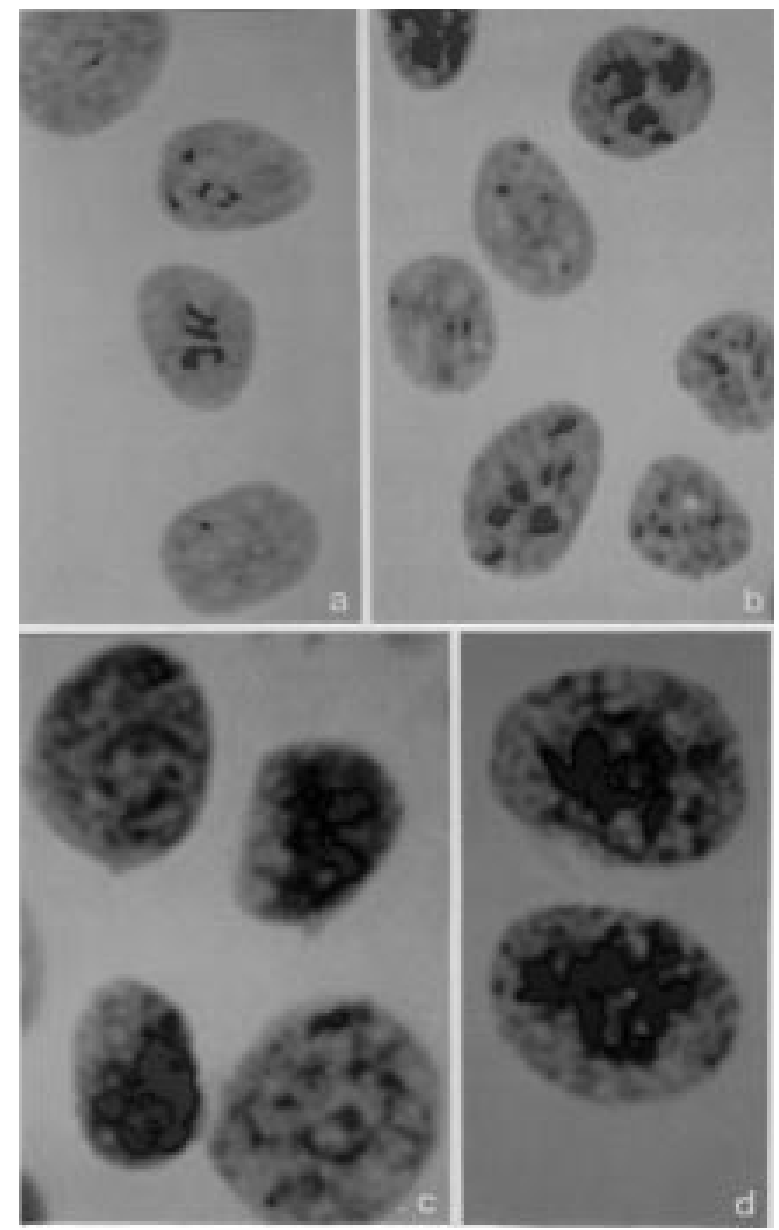

Fig. 5. Pseudocolorized nuclear images of Feulgen-stained MCF-10F cells photographed from the color monitor of the video image analyzer. Differences in "condensed" chromatin areas are evident. Segmentation identifying "condensed" chromatin particles considered the threshold level established for the control. (a): control MCF-10F cells; (b): BP1 cells; (c, d): BP1-Tras cells.

Feulgen-DNA values to the left side of the frequency histogram and also defined by comparison with neardiploid MCF-10F cell nuclei (Fig. 1, [17]). These DNA aneuploid nuclei were more frequent in BP1-E1 cells ( $>80 \%$ of the cell nuclei) although also present in BP1Tras cells $(\sim 20 \%)$ (Fig. 1).

Average absorption (OD) values were higher in BP1-Tras cell nuclei than in the other cell lines, demonstrating that in the transformed cells transfected with the Ha-ras oncogene there was an additional and general increase in chromatin packing state in comparison with that of the transformed BP1 cells and even of the BP1-E1 cells (Tables 1 and 2; Fig. 3).

BP1-Tras cell nuclei exhibited a high variability not only in Feulgen-DNA content but also in nuclear ab-
Sc\%

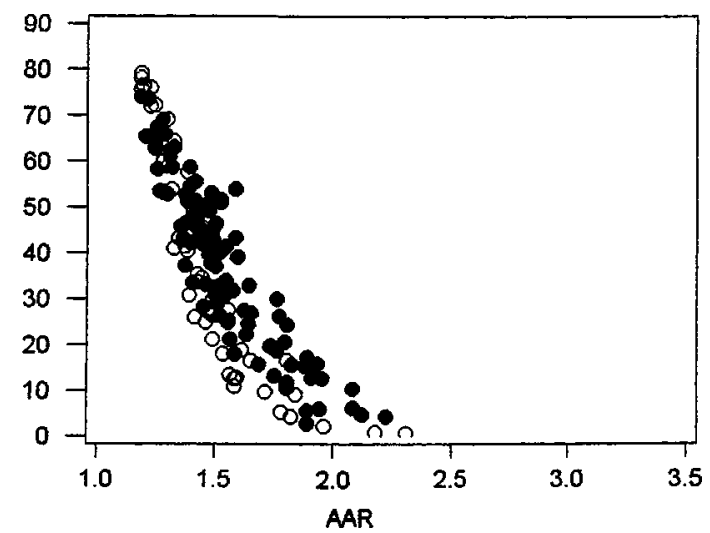

Fig. 6. Comparison of the distribution of AAR (average absorption ratio, see text) vs. Sc\% (condensed chromatin area) values between BP1 (o) $(n=55)$ and BP1-Tras cells $(\bullet)(n=100)$.

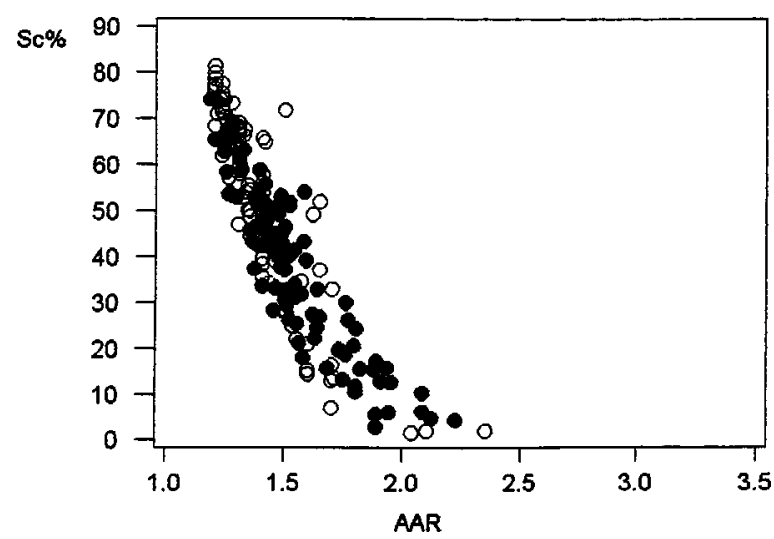

Fig. 7. Comparison of the distribution of AAR (average absorption ratio, see text) vs. Sc\% (condensed chromatin area) values between BP1-E1 cells $(\circ)(n=100)$ and BP1-Tras cells $(\bullet)(n=100)$.

sorbing areas (Table 1; Fig. 4). As regards the nuclear absorbing areas, although the BP1-Tras values did not differ significantly from MCF-10F cell values, they showed different value distribution patterns, as detected in character histograms and regression plots (data not shown). It is worth mentioning that the nuclear absorbing areas in Feulgen-stained preparations are not always comparable to those calculated for toluidine blue-stained cells, since part of the nucleolar areas may not be computed in Feulgen-stained nuclei (Fig. 5; Fig. 2 [17]). In addition, nucleolar areas in BP-transformed MCF-10F cells vary with advancing in vitro neoplastic progression [1].

The nuclear images of MCF-10F, BP1 and BP1Tras cells as seen on the monitor of the video image analyzer highlighted differences involving their "condensed" chromatin area distribution, which was especially variable in the BP1-Tras cells (Fig. 5). 


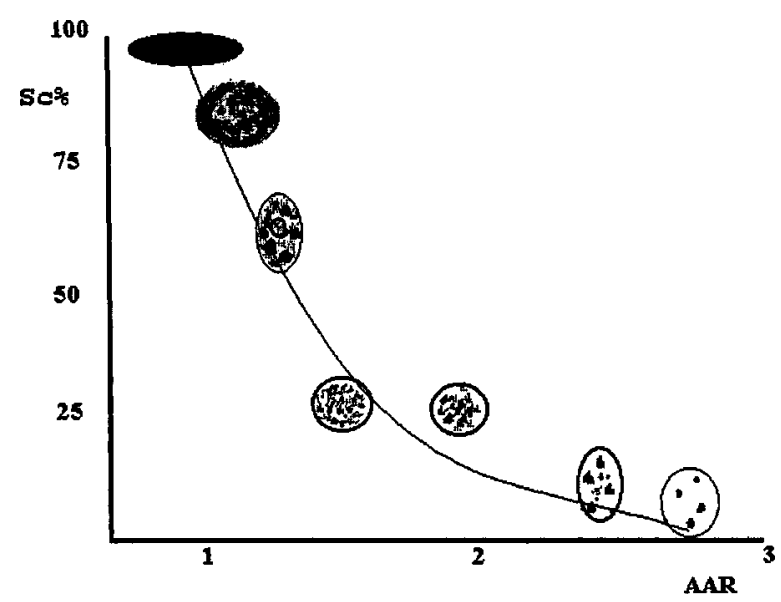

Fig. 8. Representation of positions assumed in the AAR (average absorption ratio, see text) vs. Sc\% (condensed chromatin area) scatter diagram by nuclear phenotypes differing in chromatin texture.

As regards Vidal's $[15,16]$ scatter diagram relating $\mathrm{Sc} \%$ vs AAR, part of the distribution of the points representing BP1-Tras cell nuclei differed from the distribution for nuclei of BP1 cells (Fig. 6) and for previously reported data on BP1-E1 cells [17] (Fig. 7). In comparison with a representation of positions theoretically expected for specific nuclear phenotypes into the scatter diagram (Fig. 8), it is assumed that part of the BP1-Tras values tended to show more contrast between "condensed" and "noncondensed" chromatin states when compared to BP1 cells, since the AAR values at the same corresponding $\mathrm{Sc} \%$ values were higher in BP1-Tras cells (Fig. 6). The same was valid for comparison of BP1-Tras to BP1-E1, provided the nuclear areas covered by condensed chromatin (Sc\%) did not exceed $30 \%$ of the nuclear absorbing area (Fig. 7), which in fact affected only part of the nuclear population (33\% of the BP1-Tras cells and $15 \%$ of the BP1E1 cells).

\section{Discussion}

Aggressive tumorigenic phenotypes have been found to be attained by different mechanisms in human breast epithelial cells, MCF-10F. One is obtained through progressive passages of BP-transformed cells, generating the BP1-E1 cell line [3]. The other is rapidly attained after c-Ha-ras transfection to transformed BP1 cells, giving rise to BP1-Tras cells [4].

The present image analysis data indicate that these tumorigenic human breast epithelial cell lines originated by different mechanisms exhibit different pat- terns of DNA amount changes. While BP1-E1 cells exhibited 2C DNA-aneuploidy [17], BP1-Tras cells were characterized by extreme variability in DNA content also including DNA polyploidy or near-polyploidy.

Regards chromatin texture as seen at the microscope, the extent to which nuclear areas undergoing chromatin condensation exceeds a certain threshold level increases from MCF-10F to BP1 cells, and from these ones to BP1-E1 cells [17]. In BP1-Tras cells, although an increase in chromatin condensation occurs, it apparently affects only the packing state degrees of the chromatin which had been previously condensed in BP1 cells (Tables 1 and 2, OD values; Fig. 6, AAR values). It is suggested that these changes in chromatin packing states are independent of the mitotic signaling pathway involved as previously reported for rastransformed rodent fibroblast cell lines [6]. Alterations in nuclear matrix proteins are speculated to be involved in the organization of the different chromatin higherorder packing states considered here $[6,13]$.

Considering data that demonstrated chromatin decondensation at the nucleosomal level [5,7], but chromatin condensation at the supraorganization level [8, 9] in NIH 3T3 cells with ras transformation, it may be that those areas of "condensed" chromatin in BP1-Tras cells contain some decondensed chromatin areas at the molecular level as previously hypothesized by Vidal and co-workers [17]. If this is the case, they may be involved with activated transcription [7]. In fact, a significant decrease in nucleolus number but an increase in nucleolar size found in BP1-Tras cells reflect their enhanced metabolic activities in comparison with the nontransformed MCF-10F cells and the BP1 cell line [1].

The data reveal that equally aggressive tumorigenic phenotypes in human breast epithelial cells transformed in vitro by benzo[a]pyrene, originated by different mechanisms, may be associated with different paths of DNA content and chromatin supraorganizational changes. As previously stated by Calaf and coworkers [4], the Ha-ras gene that plays a role in the early steps of the tumorigenic process in chemically transformed MCF-10F cells may additionally be involved with the tumoral progression of transformed cells. This is assumed to be favored by an enhanced genomic instability provided by the c-Ha-ras oncogene in the chemically transformed cells.

\section{Acknowledgments}

This study was supported by grants from FAPESP (95/6629-8), the Brazilian National R \& D Council 
(CNPq, 300397/96-8 and 520698/96-7) and NCI/USA (PHS-CA67238).

\section{References}

[1] L.F. Barbisan, J. Russo and M.L.S. Mello, Nuclear and nucleolar image analysis of human breast epithelial cells transformed by benzo[a]pyrene and transfected with the c-Ha-ras oncogene, Anal. Cell. Pathol. 16 (1998), 193-199.

[2] N. Barnabas-Sohi, R.C.B. Moraes, G. Calaf, S. Estrada, M.E. Alvarado and J. Russo, Overexpression of p53 protein and loss of heterozygosity in chromosome 17 in chemically transformed human breast epithelial cells, Proc. Am. Assoc. Cancer Res. 34 (1993), 109.

[3] G. Calaf and J. Russo, Transformation of human breast epithelial cells by chemical carcinogens, Carcinogenesis 42 (1993), 483-492.

[4] G. Calaf, P.L. Hang, M.V. Alvarado, S. Estrada and J. Russo, c-Ha-ras enhances the neoplastic transformation of human breast epithelial cells treated with chemical carcinogens, Intern. J. Oncol. 6 (1995), 5-11.

[5] D.N. Chadee, W.R. Taylor, R.A.R. Hurta, C.D. Allis, J.A Wright and J.R. Davie, Increased phosphorylation of histone $\mathrm{H} 1$ in mouse fibroblasts transformed with oncogenes or constitutively active mitogen-activated protein kinase kinase, J. Biol. Chem. 270 (1995), 20 098-20105.

[6] A.H. Fischer, D.N. Chadee, J.A. Wright, T.S. Gansler and J.R. Davie, Ras-associated nuclear structural change appears functionally significant and independent of the mitotic signaling pathway, J. Cell. Biochem. 70 (1998), 130-140.

[7] J. Laitinen, L. Sistonen, K. Alitalo and E. Hölttä, c-Ha-ras Val12 oncogene-transformed NIH-3T3 fibroblasts display more decondensed nucleosomal organization than normal fibroblasts, J. Cell Biol. 111 (1990), 9-17.

[8] M.L.S. Mello and J. Russo, Image analysis of Feulgen-stained c-H-ras-transformed NIH/3T3 cells, Biochem. Cell Biol. 68 (1990), 1026-1031.

[9] M.L.S. Mello, S. Contente, B.C. Vidal, W. Planding and U. Schenck, Modulation of ras transformation affecting chromatin supraorganization as assessed by image analysis, Exptl. Cell Res. 220 (1995), 374-382.

[10] M.L.S. Mello, T.Y. Lin and J. Russo, Scanning microphotometry image analysis of Ha-ras-transformed human breast epithelial cells, Anal. Cell. Pathol. 7 (1994), 301-319.
[11] M.L.S. Mello, J. Russo and B.C. Vidal, Effect of the Ha-ras oncogene on chromatin supraorganization of benzo[a]pyrenetransformed human breast epithelial cells, Proc. Am. Assoc. Cancer Res. 39 (1998), 638.

[12] M.L.S. Mello, B.C. Vidal, W. Planding and U. Schenck, Image analysis: video system adequacy for the assortment of nuclear phenotypes based on chromatin texture evaluation, Acta Histochem. Cytochem. 27 (1994), 23-31.

[13] S.K. Samuel, T.M. Minish and J.R. Davie, Altered nuclear matrix protein profiles in oncogene-transformed mouse fibroblasts exhibiting high metastatic potential, Cancer Res. 57 (1997), 147-151.

[14] H.D. Soule, T.M. Malney, S.R. Wolman, W.D. Peterson, Jr, R. Brenz, C.M. McGrath, J. Russo, R.J. Pauley, R.F. Jones and S.C. Brooks, Isolation and characterization of a spontaneously immortalized human breast epithelial cell line, MCF-10, Cancer Res. 50 (1990), 6075-6086.

[15] B.C. Vidal, Polyploidy and nuclear phenotypes in salivary glands of the rat, Biol. Cell 50 (1984), 137-146.

[16] B.C. Vidal, Image analysis and definition of nuclear phenotypes, Braz. J. Genetics 20 (1997), 749-754.

[17] B.C. Vidal, J. Russo and M.L.S. Mello, DNA content and chromatin texture of benzo[a]pyrene-transformed human breast epithelial cells as assessed by image analysis, Exptl. Cell Res. 244 (1998), 77-82.

[18] D.W. Visscher, C. Shaheen, S. Drozdowicz and J.D. Crissman, Image cytophotometric DNA histogram heterogeneity in adenocarcinoma of the breast, Anal. Quant. Cytol. Histol. 15 (1993), 206-212.

[19] Y. Wu, N. Barnabas, I.H. Russo, X. Yang and J. Russo, Microsatellite and loss of heterozygosity in chromosomes 9 and 16 in human breast epithelial cells transformed by carcinogens, Carcinogenesis 18 (1997), 1069-1074.

[20] X. Yang, Y. Huang, I.H. Russo, J.C. Barrett and J. Russo, Chromosomes 11 and 17 revert transformed phenotypes induced by benzo(a)pyrene (BP) in human breast epithelial cells (HBEC), Proc. Am. Assoc. Cancer Res. 39 (1998), 185.

[21] Zeiss Information, Continuous filter monochromator b with motor drive, Mikro Bull. 18 (1977), 1-2.

[22] P.L. Zhang, G. Calaf and J. Russo, Allele loss and point mutation in codons 12 and 61 of the c-Ha-ras oncogene in carcinogen-transformed human breast epithelial cells, Mol. Carcinogenesis 9 (1994), 46-56. 


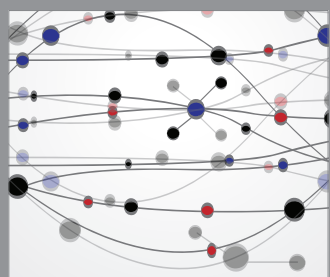

The Scientific World Journal
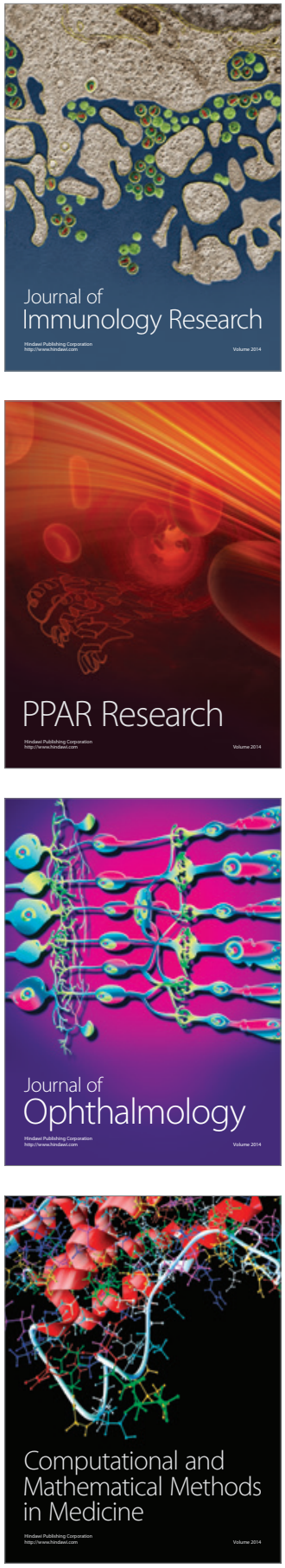

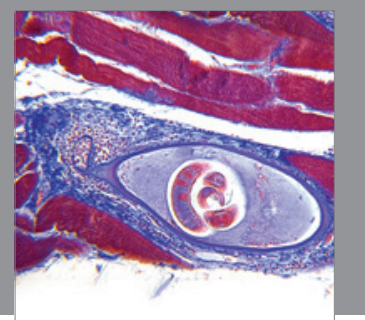

Gastroenterology

Research and Practice
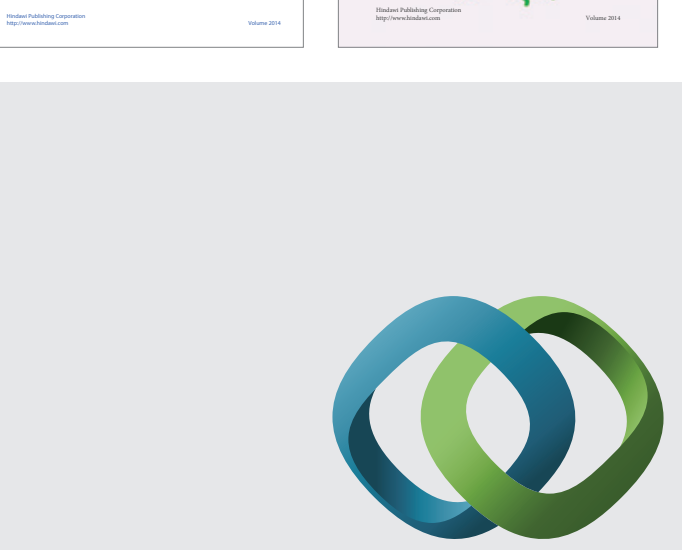

\section{Hindawi}

Submit your manuscripts at

http://www.hindawi.com
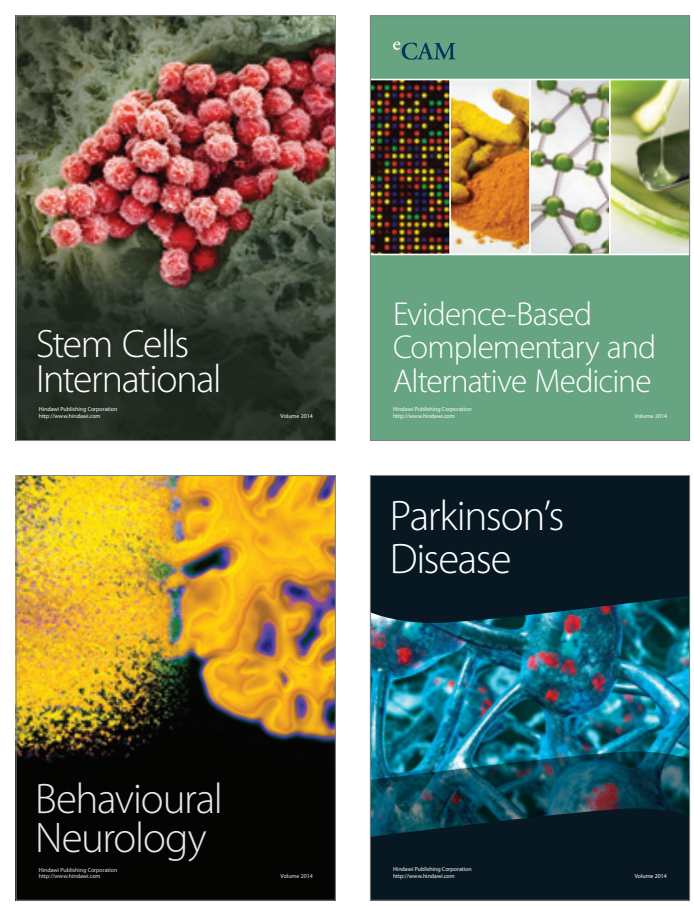

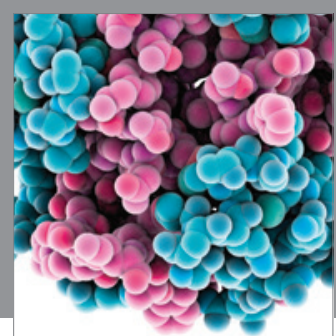

Journal of
Diabetes Research

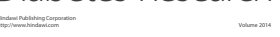

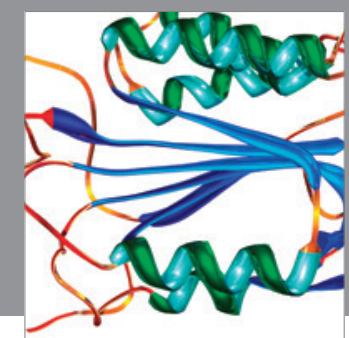

Disease Markers
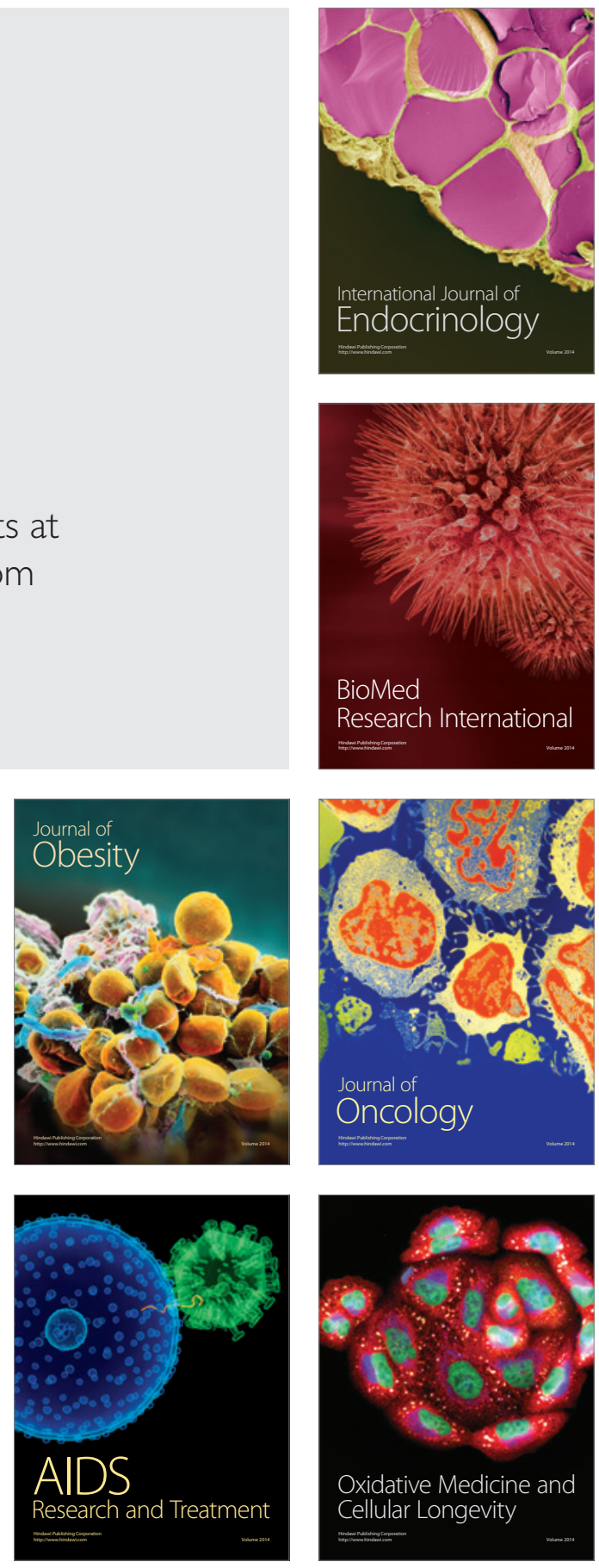